\title{
Effect of transmission line running adjacent to the circuit parameters
}

\author{
Jin Nan \\ Department of Electrical Engineering, North China Electric Power University, Baoding, China \\ Yanghe Gao, Xiangyu Li \& Jingyan Liu \\ Beijing Electrical Economy and Technology Research Institute, Beijing 100055, China
}

\begin{abstract}
In order to further calibration parameters on transmission line, it should be considered the influence of the actual conditions of the transmission line, which runs adjacent to the transmission line parameters. For single-circuit transmission line through calculation and double circuit transmission line parameters, analysis parameters affecting transmission lines near running mechanism. By MATLAB simulation experiments, simulation results further validate the new set up lines for the transport line has been put into effect, indicating the importance of the line near the line of parameters that affect the study.
\end{abstract}

KEYWORD: electromagnetic coupling; transmission line; effect parameters

\section{INTRODUCTION}

Transmission line parameters are basic parameters of the power system. Which has a very important role for power system computational analysis, relay protection aspects of setting fault location. Therefore, how to simple and accurate measure the line frequency parameters in strong electromagnetic interference environment, which has become an urgent problem to be solved.

In the actual circuit operation, also present adjacent parallel lines erected. For line parameters already running is often known, but in the case of erecting new lines have been put into operation the line will continue to exist. For the erection of a new line into operation will certainly affect the original line, then it should consider the impact of the new set up lines to the original line parameters, which can do a certain correct to the original line parameter. It can make the line parameter more accurately, to ensure the power system needs of the actual operation.

This paper mainly for parallel erection of double-circuit transmission line, considering the electromagnetic coupling and on-ground capacitance between its lines. Establishing parallel double-circuit transmission line model to analyze the principle about the effect of electromagnetic coupling for line parameters between its lines, and finally verify the conclusion by simulation.

\section{INFLUENCE MECHANISM}

For resistance parameters and conductivity parameters are generally only with line properties and the surrounding environment. These parameters typical values are relatively small, and are calculated by a simple formula. For reactance and admittance parameters, generally are affected by the distribution lines, the surrounding environment more obvious, so the main study is single-circuit and double-circuit transmission line reactance and susceptance parameter.

\subsection{Single-circuit transmission line}

For the calculation of the single-circuit transmission line parameters can be divided into positive sequence calculation parameters and zero sequence parameters. For positive parameter of the power line, parameters of the distribution line is mainly related with the model and each phase conductor. The new erecting transmission lines has small impact for transmission lines.

Zero sequence impedance single-circuit transmission line parameters is calculated as follows.

Equivalent depth:

$D_{g}=660 / \sqrt{f \gamma}$

Geometric mean distance:

$D_{s}=\sqrt[3]{r^{\prime} D_{m}}$

Zero sequence equivalent impedance of each phase conductor:

$z_{0}=R_{a}+3 R_{g}+j 0.4335 \log \frac{D_{g}}{D_{s}}$

$\mathrm{Ra}$ is the resistance of the wire. $\mathrm{Rg}$ is the earth resistance. If $\mathrm{f}$ is equal to $50 \mathrm{HZ} \mathrm{Rg}$ is equal to $0.05 \Omega / \mathrm{km}$.

Considering the impact of overhead ground, calculate as follows: 
Zero sequence mutual impedance of three phase conductors and over-head ground:

$z_{c w 0}=3 R_{g}+j 0.4335 \log \frac{D_{g}}{D_{c-w}}$

$D_{c-w}$ is the geometric mean distance of overhead ground wire and three-phase interaction.

For zero sequence impedance per phase of single circuit overhead transmission line with overhead ground wire,

$z_{0}^{w}=z_{0}-\frac{z_{c w 0}^{2}}{z_{w 0}}$

$Z_{w 0}$ is the self-impedance of overhead ground wire. That is related to the property itself of overhead ground wire, overhead ground wire geometry and soil resistivity.

When there are two ground wires, due to the distribution of the ground changes, overhead ground wire and overhead transmission lines mutual parameters vary. The equivalent radius of the original overhead ground wire will become relate with the overhead ground distance. Mutual parameters to be considered the geometric mean distance of two overhead ground wire influence.

Susceptance is calculated as follows:

The self-geometric mean distance of three phase conductors:

$D_{s}=\sqrt[3]{r D_{m}^{2}}$

Their mutual mirroring geometric mean distance of three phase conductors:

$H_{m}=\sqrt[9]{H_{1} H_{2} H_{3}\left(H_{12} H_{23} H_{31}\right)^{2}}$

Zero sequence suscepance of each phase:

$b_{0}=\frac{7.58}{3 \log \frac{H_{m}}{D_{s}}} \times 10^{-6}$

Since the charge in aerial and ground line on the wire inverted, can be understood as the earth potential of zero sequence raised, which makes overhead ground zero sequence capacitance increases.

Each phase zero sequence capacitance of singlecircuit overhead transmission line with ground line:

$c_{0}^{w}=\frac{0.0241}{3\left(\log \frac{H_{m}}{D_{S}}-\frac{\left(\log \frac{H_{c W}}{D_{C W}}\right)^{2}}{\log \frac{H_{W}}{D_{S W}}}\right)} \times 10^{-6}$

$\mathrm{H}_{\mathrm{m}}$ is mutual geometric mean distance between overhead wires and its mirroring. $\mathrm{H}_{\mathrm{w}}$ is mutual geometric mean distance between ground and mirroring. $\mathrm{H}_{\mathrm{cw}}$ is mutual geometric mean distance between one back mirror and overhead ground wire. $\mathrm{D}_{\mathrm{cw}}$ is mutual geometric mean distance between ground wire and one back line. $\mathrm{D}_{\mathrm{sw}}$ is geometric mean distance of overhead ground wire.

\subsection{Double-circuit transmission line}

For double-circuit positive sequence parameters, the original line in the vicinity of the original line conductors created a newly circuit transmission lines major changes the distribution of each phase, the impact on the positive sequence parameters in terms of the whole line being not large. It is almost no influence on resistance and conductivity parameters, but for the reactance and susceptance parameter, due to changes in the distribution line will affect the original line geometric mean, thereby affecting the amount of the original line. Erection of new lines for the impact of the original line can be represented by a Factor $\alpha$.

Suppose the original line reactance is $\mathrm{x} 1$. After the erection of the new line, the original line reactance become $\mathrm{x} 2$. It assumed $\alpha$ is ratio of $\mathrm{x} 1$ to $\mathrm{x} 2$.

$\alpha=\frac{\log \frac{D_{m 2}}{r^{\prime}}}{\log \frac{D_{m 1}}{r^{\prime}}}=\frac{\log \alpha_{1} \frac{D_{m 1}}{r^{\prime}}}{\log \frac{D_{m 1}}{r^{\prime}}}$

For the similarly affected with positive sequence susceptance parameters, but the impact becomes $1 / \alpha$.

For Double zero sequence parameters, the two parallel back lines have the same zero-sequence current direction to the three-phase overhead transmission line. The new set up circuit three-phase can help the mutual inductor of the original circuit three-phase line, which makes the zero sequence impedance of the circuit further increased. But taking into account the impact of overhead ground wire, zero-sequence impedance will be reduced. It is equivalent to a short circuit wire coil next to the overhead ground wire and overhead ground lines and the ground are the zero sequence current loop, so current overhead ground wire in the opposite direction of transmission line zero sequence current, and thus the overhead ground wires playing demagnetization, the distance more recent, the greater effect of demagnetization.

The zero sequence mutual impedance does not considering transposition of double circuit overhead ground,

$Z_{I-I I}=3 R_{g}+j 0.4335 \log \frac{D_{g}}{D_{I-I I}}$

$D_{\text {I-II }}$ is mutual geometric mean distance of two loops,

$$
D_{I-I I}=\sqrt[9]{D_{a d} D_{a e} D_{a f} D_{b d} D_{b e} D_{b f} D_{c d} D_{c e} D_{c f}} \text { (12) }
$$

Zero sequence impedance of each circuit when the two circuits are identical,

$z_{0}^{(2)}=z_{0}+z_{I-I I}$

For double circuit overhead transmission line with overhead ground wire, its zero-sequence impedance per phase has some changes. In addition to the zerosequence impedance from the original line, should also consider the zero-sequence impedance between the new and original lines. While the new additional overhead ground wire will produce the same effect on the transmission line, reducing transmission line zero sequence impedance to a certain extent. Zero sequence impedance parameters are calculated as follows:

$z_{0}^{(2, w)}=z_{0}+z(I-I I) 0-2 \frac{z_{c w 0}^{2}}{z_{w 0}}$

Double-zero-sequence capacitance, compared with the single circuit line zero sequence capacitance, since the double-circuit line zero-sequence current in the same direction, double-circuit line zero sequence capacitance become small. 
$c_{0}^{2}=\frac{0.0241}{3\left(\log \frac{H_{m}}{D_{s}}+\log \frac{H_{I I I}}{D_{I I I}}\right)} \times 10^{-6}$

$H_{\text {I II }}$ is between circuit I and mirror II. $D_{\text {I II }}$ is mutual geometric between circuit I and circuit II .

\section{SIMULATION ANALYSIS}

Select the parallel erection single-circuit line. Threephase wire model is $2 \times$ LGJ-300. Split spacing is $40 \mathrm{~cm}$, with distance from the middle line are $9 \mathrm{~m}$. Overhead ground wire is $2 \times \mathrm{GJ}-50$, and $\mathrm{D}_{\mathrm{w}}$ is $13 \mathrm{~m}$. The ground and the three-phase the average distance between the wires is $8 \mathrm{~m}$. Three-phase wire from the ground as the average height is $16 \mathrm{~m}$. Overhead ground wire is apart from the ground an average height of $24 \mathrm{~m}$. Using MATLAB calculate two back lines separated by $10 \mathrm{~m}, 20 \mathrm{~m}, 30 \mathrm{~m}, 50 \mathrm{~m}, 100 \mathrm{~m}$, to simulate the situation analysis and compare different line parameters with the change distance of doublecircuit line.

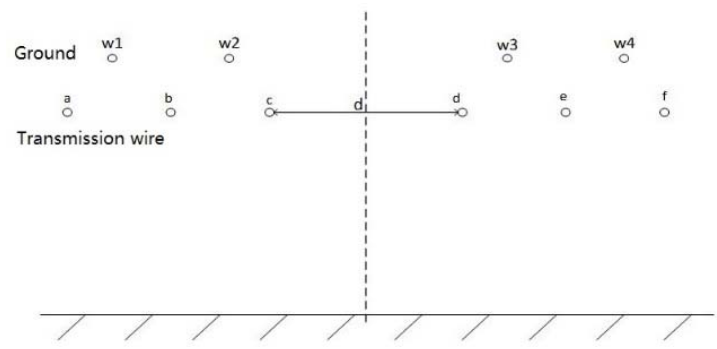

Figure.3 Distribution diagram of double circuit transmission lines

Table1 Parameter values for different distances

\begin{tabular}{|l|l|l|l|l|l|l|}
\hline & 1 & C1 & L0 & C0 & Lm & Cm \\
\hline $\begin{array}{l}\text { One } \\
\text { back } \\
\text { line }\end{array}$ & $.0419 \mathrm{e}-03$ & $1.1201 \mathrm{e}-08$ & $3.4683 \mathrm{e}-03$ & $7.4977 \mathrm{e}-09$ & & \\
\hline $10 \mathrm{~m}$ & $.0417 \mathrm{e}-03$ & $1.1267 \mathrm{e}-08$ & $3.2727 \mathrm{e}-03$ & $7.7478 \mathrm{e}-09$ & $1.7414 \mathrm{e}-03$ & $-9.1191 \mathrm{e}-10$ \\
\hline $20 \mathrm{~m}$ & $.0418 \mathrm{e}-03$ & $1.1216 \mathrm{e}-08$ & $3.2996 \mathrm{e}-03$ & $7.5790 \mathrm{e}-09$ & $1.5621 \mathrm{e}-03$ & $-4.7795 \mathrm{e}-10$ \\
\hline $30 \mathrm{~m}$ & $.0418 \mathrm{e}-03$ & $1.1206 \mathrm{e}-08$ & $3.3189 \mathrm{e}-03$ & $7.5315 \mathrm{e}-09$ & $1.4342 \mathrm{e}-03$ & $-2.9439 \mathrm{e}-10$ \\
\hline $50 \mathrm{~m}$ & $.0418 \mathrm{e}-03$ & $1.1202 \mathrm{e}-08$ & $3.3459 \mathrm{e}-03$ & $7.5065 \mathrm{e}-09$ & $1.2500 \mathrm{e}-03$ & $-1.4314 \mathrm{e}-10$ \\
\hline $100 \mathrm{~m}$ & $.0417 \mathrm{e}-03$ & $1.1201 \mathrm{e}-08$ & $3.3836 \mathrm{e}-03$ & $7.4987 \mathrm{e}-09$ & $9.6605 \mathrm{e}-04$ & $4.6354 \mathrm{e}-11$ \\
\hline
\end{tabular}

It is shown that the positive sequence parameters remained unchanged, only being a certain amount affected within $20 \mathrm{~m}$. It decreases the positive sequence impedance parameters, increase positive sequence capacitance parameter. The influence on zero sequence parameters is relatively clear. Zero-sequence inductance parameter increases with the distance increases but is always less than the case of single-circuit transmission line. The zero-sequence capacitance parameters is reduced, but it always greater than the singlecircuit line zero-sequence capacitance parameters. For mutual zero sequence parameters, the absolute value of the parameters are gradually reduced with the distance increases.
Table2 Zero sequence inductance and capacitance variation under different distance

\begin{tabular}{|l|l|l|l|l|}
\hline & L0 & L\% & C0 & C $\%$ \\
\hline One back line & $3.4683 \mathrm{e}-03$ & & $7.4977 \mathrm{e}-09$ & \\
\hline $10 \mathrm{~m}$ & $3.2727 \mathrm{e}-03$ & $5.64 \%$ & $7.7478 \mathrm{e}-09$ & $3.34 \%$ \\
\hline $20 \mathrm{~m}$ & $3.2996 \mathrm{e}-03$ & $4.68 \%$ & $7.5790 \mathrm{e}-09$ & $1.08 \%$ \\
\hline $30 \mathrm{~m}$ & $3.3189 \mathrm{e}-03$ & $4.31 \%$ & $7.5315 \mathrm{e}-09$ & $0.451 \%$ \\
\hline $50 \mathrm{~m}$ & $3.3459 \mathrm{e}-03$ & $3.53 \%$ & $7.5065 \mathrm{e}-09$ & $0.117 \%$ \\
\hline $100 \mathrm{~m}$ & $3.3836 \mathrm{e}-03$ & $2.44 \%$ & $7.4987 \mathrm{e}-09$ & $0.001 \%$ \\
\hline
\end{tabular}

It is shown that in the short distance erecting new transmission line have some impact on the transmission line has been in operation, because of the importance of zero-sequence line parameters in fault location, protection, etc. So checking the original parameters is necessary.

\section{CONCLUSION}

For creating a new line in the vicinity of the original back line, due to the impact of the new lines and overhead ground wire for the original three-phase line, the original line parameter is bound to change. The new setting up three-phase primary line will increase the reactance parameters and reduce the capacitance parameters. The new setting up ground line will reduce the reactance parameters and increase the capacitance parameters. It should consider the impact of new set up transmission lines, checking on the original line parameters.

\section{REFERENCE}

Li Guangqi. 2007. Transient Analysis of Power System. China Electric Power Press: 109-116.

$\mathrm{Wu}$ Changqing. 2012. Power Frequency Parameter Online Measurement of Transmission Line Based on Synchronous Data of Both Ends. North China Electric Power University, 40(8):126-129.

Zhao Yanjun. 2015. A new method for measuring power frequency impedance parameters of double circuit transmission lines on the same tower. Transactions of China Electrotechnical Society, 30(2): 256-264. 